\title{
The Adult Carer Quality of Life Questionnaire (AC-QoL): comparison with measures of burden and well-being, and Italian validation
}

\author{
Negri L., Piazza G., Sartori R.D.G., Cocchi M.G., Delle Fave A.
}

\section{ABSTRACT}

Purpose: Family caregivers are essential assets in the rehabilitation process, and their psychophysical health should represent a concern for healthcare services. This study aims to investigate the psychometric properties of the Adult Carer Quality of Life Questionnaire, Italian version, and its convergent-discriminant validity with measures of caring burden, resilience, health and well-being.

Materials and Method: Participants were 591 parents (89.2\% females; aged 25-69) of children treated as outpatients in 14 centers of "Istituto Medea - La Nostra Famiglia", an Italian rehabilitation institution. They completed: Adult Carer Quality of Life Questionnaire, a 40-item scale assessing care-related challenges, resources and benefits; Caregiver Burden Inventory; Resilience Scale for Adults; Satisfaction With Life Scale; Health Survey. The psychometric properties of the Adult Carer Quality of Life Questionnaire were investigated through exploratory and confirmatory factor analyses and reliability evaluation; correlation coefficients assessed convergent and discriminant validity with burden and well-being measures.

Results: The original eight-factor structure of the Adult Carer Quality of Life Questionnaire showed good adequacy and internal consistency; convergent and discriminant validity with measures of burden, resilience, satisfaction, physical and mental health were satisfactory.

Conclusions: The Italian version of the Adult Carer Quality of Life Questionnaire is a reliable and valid instrument to assess caregivers' perceived challenges and resources. As a parsimonious and easily administrable tool, it can be used to evaluate caregivers' quality of life and related interventions.

Key words: Caregivers - Burden - Well-Being - Adult Carer Quality of Life Questionnaire - Psychometric properties - Validation 


\section{Introduction}

The increasing life expectancy and the prevalence of disabling pathologies at all life stages across countries make family caregivers invaluable resources for the healthcare system $[1,2]$. Nevertheless, the needs of this essential category of citizens are primarily addressed by noprofit associations, that offer training programs, counseling, and respite care services. Studies evaluating the efficacy of these interventions are limited; moreover, the diversity of intervention approaches and the predominant focus on specific pathologies, such as dementia and cancer, make generalizations and comparisons of findings arduous. Further research efforts in this domain are thus necessary, especially as concerns the identification of welldefined and measurable indicators of caregivers' quality of life, a crucial step to adequately design and evaluate intervention programs.

\section{The burden and resources of caregivers}

Several studies have investigated the problematic aspects of caregiving, differentiating the strain specifically related to the caring role from the psychological distress that can derive from a variety of life events. Caregiving strain is usually assessed as burden, a construct comprising objective and subjective components such as the amount of time daily devoted to caring activities, financial issues and social role limitations, feelings of anger, exhaustion, guilt, choice constraint, and frustration [3,4] The prominent predictors of caregivers' burden include type and severity of the care-recipient's disease, as well as carer's demographic features [5]. Several scales were developed to assess caring-related burden and its relation with quality of life [6]. 
Nevertheless, exposure to distress in relation to the caregiving role does not prevent family caregivers to report satisfactory levels of psychosocial adjustment. These findings, confirmed across categories of family caregivers, including parents of children with disabilities [7-9], suggest that the negative dimensions of caring burden co-exist with positive aspects, consisting in psychological, social and material resources that contribute to the well-being and quality of life of caregivers.

Measures specifically assessing the positive aspects of caregiving are scarce. Studies involving parents of children with disabilities are predominantly focused on the assessment of general constructs such as locus of control, satisfaction with life, psychological wellbeing, and quality of social connections [10-13]. Notably, the recent report of the Family Caregiver Alliance does not include measures of positive caring dimensions [6].

Among the constructs identified in the well-being literature, resilience is specifically suited to investigate caregivers' experience, as it refers to the ability to achieve satisfactory levels of psychosocial adjustment despite adverse circumstances [14]. From this perspective, an adverse event like the disease of a family member may become an opportunity for caregivers to redefine their personal developmental trajectories, and to strengthen family and community relations [15-18].

\section{The Adult Carer Quality of Life Questionnaire (AC-QoL)}

In the attempt to more exhaustively evaluate caregivers' experience, the Adult Carer Quality of Life Questionnaire (AC-QoL) was designed to capture both positive and negative aspects of caring [19]. It includes 40 items grouped into eight dimensions, reflecting the major components of the caring role identified by the literature: environmental aspects, represented by social support and financial resources; perceived burden, evaluated as stress and limitations in freedom and choices; caring related benefits, including personal growth, the 
feeling of being valued and appreciated by the care recipient, skills and competences, and satisfaction with caring.

A preliminary psychometric evaluation of the instrument provided encouraging results [19]. AC-QoL is relatively short, it can be self-administered, and the item contents are suited to any caregiver typology, regardless of the specific pathology, age or family relationship with the care-recipient.

\section{Aims}

Two aims guided the present study. The first one was to analyze the psychometric properties of the Italian version of AC-QoL. The second aim was to investigate, for the first time at the international level, the instrument's convergent and discriminant validity with measures of caring burden, resilience and well-being.

As concerns the first aim, we expected to replicate the instrument's original 8-factor structure. In line with the original study, we also expected to detect very low correlations between AC-QoL scores and sample demographics (in particular, age and gender). Finally, in line with the literature on caregiving, we hypothesized to find a negative correlation between AC-QoL and care-recipient disease severity.

As concerns the second aim, we expected to detect convergence between AC-QoL subscales addressing caring stress and choice constraints and a measure of burden, and between subscales assessing psychological and interpersonal resources and a measure of resilience. To investigate the discriminant validity of AC-QoL, we analyzed the relationship between the subscales assessing the positive facets of caregiving and general measures of health and well-being. As the psychological assets assessed by AC-QoL are specifically related to caregiving, we expected to find low correlations between them and global wellbeing measures. 


\section{Materials and methods}

Participants were recruited at "Istituto Medea - La Nostra Famiglia", an Italian institution providing healthcare and psychosocial services to children diagnosed with disabling diseases and their families. Eligible participants were parents of children aged 6-18 diagnosed with pathologies varying in clinical features and severity, and treated as outpatients in 14 centers of the institute located in six different regions.

All the study procedures were conducted in accordance with the ethical standards of the institutional and national research committee and with the Helsinki declaration and its later amendments. After project approval by the institution's Ethical Committee (protocol number: 032/14-CE; date of approval: 29/04/14), the healthcare personnel contacted eligible caregivers by phone or at the centers in occasion of their children's therapy sessions. Interested parents received detailed information on the project, signed an informed consent in compliance with Italian privacy rules, and were provided with a battery of questionnaires that could be completed in situ or autonomously at home. Participants' anonymity and freedom to leave the project were guaranteed in all research phases. Data were collected between June 2014 and December 2015.

\section{Measures}

The Adult Carer Quality of Life Questionnaire (AC-QoL) includes 40 items on 4-point scales $(0=$ never; $1=$ some of the time; $2=$ a lot of the time; $3=$ =always $)$, grouped into eight subscales: support for caring (items 1-5), caring choice (items 6-10), caring stress (items 1115), money matters (items 16-20), personal growth (items 21-25), sense of value (items 2630), ability to care (items 31-35), and carer satisfaction (items 36-40) [19]. Median values can be calculated for each item, and summed values for each dimension and for the total 
score. Higher values correspond to higher quality of life for 26 items, while the 14 negatively worded items require a reverse coding procedure. As a result, higher values correspond to a better quality of life both for all subscales and AC-QoL total score.

Total scores range between 0 and 120 . According to the user's manual, low quality of life corresponds to $0-40$ scores, mid-range quality of life to $41-80$, and high quality of life to scores higher than 80. Two expert researchers translated the AC-QoL into Italian, and a native English professional performed the back translation.

In order to investigate AC-QoL convergent and discriminant validity, participants were also administered the following instruments in the validated Italian version:

Caregiver Burden Inventory (CBI) [3,20]. It comprises 24 items on 0-4 Likert-type scales, grouped into five dimensions: time dependence, developmental burden, physical burden, social burden and emotional burden. Total scores range between 0 and 96: scores between 24 and 36 indicate caregivers' need for respite, while scores above 36 indicate risk of burnout. Cronbach's alpha value for the current study data was .92.

Resilience Scale for Adults (RSA) [21,22]. It comprises 33 items on 1-5 semantic differential scales grouped into six subscales: family cohesion and support, social resources, self-efficacy and self-esteem, future plans, social competences, and social support. The total score represents the sum of the item values. Following the approach adopted in previous studies [18], high levels of resilience correspond to total scores raging 33-77, moderate levels to scores in the 78-121 range, and low levels to scores above 122 (Cronbach's alpha for this study data=.90).

Satisfaction with Life Scale (SWLS) [23,24]. This widely used well-being measure assesses the cognitive component of subjective well-being (general life satisfaction) and comprises five items on 7 point scales. Cronbach's alpha amounted to .90 for the current study data. 
Short Form Health Survey (SF-36, version 1) [25,26]. The instrument investigates the levels of physical and mental health perceived within the previous four weeks through 36 items grouped into eight dimensions. For the purposes of this study two subscales were selected: role limitations due to physical problems (RLP), and general mental health (MH), reflecting the global perception of physical and mental well-being respectively. Higher scores indicate a better health status. Values range from 0 (worst health) to 100 (best health) in each dimension. Cronbach's alpha for MH was .82; reliability of RLP subscale (dichotomous) was assessed through KR-20 formula and amounted to .83.

\section{Statistical analyses}

Due to the complexity of the analytical procedure, only questionnaires with a maximum of two missing values for AC-QoL and RSA, one for CBI and none for SWLS were retained for analyses. Missing values were replaced by items' median scores. Descriptive statistics were then calculated for AC-QoL items. Considering that 4-point rating scales are in fact ordinal, besides mean and standard deviation median values, ranges and interquartilic distances were calculated.

In line with the study aims, the factor structure of the AC-QoL Italian version was first investigated. The full sample was randomly split into two halves, labeled as subsample 1 and 2, each reproducing the distribution of caregivers' age and child disease severity characterizing the whole sample.

Exploratory factor analysis (EFA) was performed on subsample 1. Due to the ordinal nature of the data, the robust weighted-least square approach (WLSMV) provided by Mplus was employed. The final number of factors to be retained was identified through the use of two selection methods: Kaiser-Guttman's criterion and Cattell's scree test. Only factors 
showing eigenvalues greater than 1 or positioned to the left of the inflexion point on the eigenvalue plot were further inspected.

In order to explore the structure of factors that were theoretically expected to correlate, an oblique rotation method (direct oblimin) was employed.

Confirmatory factor analysis (CFA) was then conducted on subsample 2, this technique was employed since it has never been used before to test AC-QoL factor structure. Moreover, Structural Equation Modelling (SEM) allows the superimposition of constraints replicating the hypothesized structure of the questionnaire in order to calculate several index of model fit that are not saturated as in EFA.

In both EFA and CFA the model goodness of fit was assessed through robust WLSMV Chi-Square $(\chi 2)$ and three indexes: the Root Mean Square Error of Approximation (RMSEA), an index of absolute fit, employed to evaluate model complexity as reflected in the degrees of freedom; the Comparative Fit Index (CFI) and Tucker Lewis Index (TLI), both measuring improvements in model fit through comparison between the hypothesized model and the baseline one. In addition, the model goodness of fit in EFA was tested through the Standard Root Mean Square Residual (SRMR), an index evaluating the average difference of standardized residuals between the observed and the hypothesized covariance matrices. All these indices were shown to perform reasonably well with categorical model estimation [27]. Model fit acceptability was evaluated through the following cut-off criteria: RMSEA<.08, CFI and TLI $>.90$, SRMR $<.08[28,29]$.

Internal consistency of AC-QoL was assessed on the whole sample through Cronbach's alpha for ordinal variables using the categorical principal component analysis procedure (CATPCA) in SPSS ver. 23 [30]; inter-item and corrected item-scale correlations were also evaluated through polychoric and polyserial correlation coefficients. 
In order to ascertain the instrument's convergent and discriminant validity, descriptive statistics were calculated for all measures. The relationship between AC-QoL total and subscale scores and the other measures' scores was assessed through Spearman's correlation coefficient, that allows to account for the non-normality of data distribution. The correlations between AC-QoL and participants' demographic features were evaluated through Spearman and rank biserial coefficients. In line with the literature, regardless of the statistical significance only coefficient values equal to or higher than .30 were considered as adequate to interpret associations as meaningful. Above this threshold, values between .30 and .50 were interpreted as indices of low correlation, values between .50 and .70 as indices of moderate correlation, and values above .70 as indices of high correlation between variables [31].

\section{Results}

\section{Participants}

Out of the 652 caregivers who agreed to participate in the study, 61 were excluded from analyses as the number of missing data in their questionnaires exceeded the established threshold. Therefore, the final sample comprised 591 participants aged 25-69. Table 1 summarizes their demographic characteristics.

\section{---- TABLE 1 ABOUT HERE ----}

The degree of child disease severity (low/mild vs. high) was clinically determined through the International Statistical Classification of Diseases $10^{\text {th }}$ Revision (ICD-10) [32]. Mental and behavioral disorders represented the prominent primary diagnoses (Group F, 60.7\%), followed by nervous system diseases (Group G, 24.4\%), congenital malformations and chromosomal abnormalities (Group Q, 6.6\%), and eye diseases (Group H, 3.4\%); the 
remaining $4.9 \%$ included other diagnoses.

\section{Descriptive statistics of AC-QoL}

Table 2 illustrates the descriptive statistics of AC-QoL items, calculated on the whole sample. Items are numbered and their content is synthetically described.

\section{---- TABLE 2 ABOUT HERE ----}

\section{Construct validity}

Exploratory factor analysis was conducted on subsample 1. Sampling adequacy was preliminarily verified through Kaiser-Meyer-Olkin (KMO) measure. Total KMO amounted to .90 , and all KMO values for single items were higher than .70, thus above the acceptability limit of .50 [33]. Bartlett's test of sphericity $\left(\chi^{2}(780)=6961.08, p<.001\right)$ indicated that correlations between items were sufficiently large to perform EFA. Eight factors showed eigenvalues above Kaiser-Guttman's criterion of 1. Scree plot's inflexion point suggested the adequacy of solutions including four and seven factors as well. The 4factor solution showed an unsatisfactory goodness of fit (WLSMV $\chi 2(626)=2223.21, p<.001$; RMSEA=.093; CFI=.880; TLI=.850; SRMR=.08). Indices were instead acceptable for the 7factor solution $\left(\mathrm{WLSMV} \chi^{2}(521)=878.41, p<.001 ; \mathrm{RMSEA}=.048 ; \mathrm{CFI}=.973 ; \mathrm{TLI}=.960\right.$; $\operatorname{SRMR}=.034)$ and the 8 -factor one $(\operatorname{WLSMV} \chi 2(488)=707.04, p<.001 ; \operatorname{RMSEA}=.039$; $\mathrm{CFI}=.983 ; \mathrm{TLI}=.974 ; \mathrm{SRMR}=.028$ ). Although both models were evaluated, the description of results will only focus on the 8-factor solution, theoretically and empirically consistent with the original AC-QoL model.

Table 3 shows AC-QoL factor loadings after oblimin rotation. 
Most items showed the largest loadings (>.53) on the expected factor and very low crossloadings (<.30), thus confirming the original model adequacy. Only items 37 and 38 did not show a clear-cut loading pattern on the expected factor (carer satisfaction); in particular, item 37 showed the highest loading on caring stress. Finally, the factor loading for item 23 exceeded 1. Although this could be interpreted as a Heywood case, residual variance for the item was positive (.013) and no error or warning message were obtained from the Mplus estimation procedure. The high percentage of variance shared by the item and the corresponding factor can be related to the strong content similarity between the item ("Because of caring, I feel that I have grown as a person") and the latent factor (personal growth) [34]. The investigation of the 7-factor solution through EFA confirmed the recurrence of six of the factors detected in the 8 -factor solution, while the seventh factor subsumed caring choice and caring stress, including items 37 and 38 as well.

To further test the adequacy of the two solutions, confirmatory factor analyses were performed using subsample 2. The goodness of fit indices were satisfactory for both models: $\operatorname{WLSMV} \chi^{2}(719)=1448.48, p<.001 ; \mathrm{RMSEA}=.059 ; \mathrm{CFI}=.946 ; \mathrm{TLI}=.941$ for the 7 -factor solution, and $\operatorname{WLSMV} \chi^{2}(712)=1356.20, \mathrm{p}<.001 ; \mathrm{RMSEA}=.055 ; \mathrm{CFI}=.952 ; \mathrm{TLI}=.948$ for the 8-factor one. Since WLSMV does not allow for comparing the models' goodness of fit through Akaike's Information Criterion (AIC) and Bayesian Information Criterion (BIC), we analyzed the 7-factor model as nested into the 8-factor one. Caring choice and caring stress, empirically aggregated in the 7-factor model, were collapsed into one factor by imposing two constraints: their reciprocal correlation to be 1 , and their correlations with the other factors to be equal. This strategy allowed for comparing the two models' WLSMV $\chi^{2}$ using the DIFFTEST command in Mplus. The significant difference obtained: $\Delta \chi^{2}(7)=60.781$, $p<.001$, suggested that the 8 -factor model, including more freely estimated parameters, fits the data better than the smaller 7-factor one. 
The standardized loadings obtained through CFA for the 8-factor model are reported in Table 4.

\section{---- TABLE 4 ABOUT HERE ----}

Overall, items showed high loadings (between .59 and .92) on the expected factor. At the same time, as illustrated in Table 5, significant correlations were detected among all the factors, except for money matters. Retaining only coefficient values above .30 as reliable indices of association, a high correlation emerged between caring choice and caring stress, the burden related dimensions aggregated in the 7-factor solution obtained from EFA. Moderate correlations were found among personal growth, sense of value, and ability for caring - factors referring to positive facets of caregiving. Carer satisfaction was moderately to highly correlated with six factors. Support for caring showed a moderate correlation with caring choice and caring stress, and a low correlation with caring ability, sense of value and personal growth.

\section{---- TABLE 5 ABOUT HERE ----}

Finally, CFA was performed on the total sample adopting the 8-factor solution. The goodness of fit indices were satisfactory: $\operatorname{WLSMV}^{2}(712)=2116.52, p<.001$; $\operatorname{RMSEA}=.058$; $\mathrm{CFI}=.948 ; \mathrm{TLI}=.943$.

\section{Internal consistency}

Cronbach's alphas, inter-item and corrected item-scale correlations were evaluated on the whole sample as a measure of AC-QoL internal consistency. Cronbach's scores for the eight subscales (Table 6) ranged from .79 to .90 , showing acceptable to excellent levels of reliability; alpha coefficient for the AC-QoL summed score was also excellent (.93). All items showed correlation values higher than .40 with the elements of the same subscale, 
except for three items $(18,19$ and 20) of the money matters subscale and two items (37 and 38 ) of the carer satisfaction subscale. Item 18 showed correlation values of .26 and .39 with items 19 and 20 respectively, while item 19 and 20 showed a polychoric correlation of .39 .

As for carer satisfaction subscale, item 37 showed correlation values of $.31, .37$ and .39 with item 36, 39 and 40 respectively, while item 38 showed correlation indexes of .31 and .39 with item 36 and 39. Nevertheless, all corrected item-scale correlation coefficient values ranged from .46 (item 37) to .85 (item 23) (Table 6), well above the threshold of .30 [35].

---- TABLE 6 ABOUT HERE ----

\section{Convergent and discriminant validity}

Table 7 reports AC-QoL total and subscale scores, total scores of Caregiver Burden Inventory, Resilience Scale for Adults and Satisfaction With Life Scale, as well as the scores of Role Limitations due to Physical Problems and Mental Health subscales of SF-36. All the scores were calculated on the whole sample.

\section{---- TABLE 7 ABOUT HERE ----}

As concerns AC-QoL, participants perceived high quality of life, both at the global score level and in six subscales, reporting the highest score for sense of value. Social support and money matters scored instead in the mid-level range.

Caregiver burden levels were compatible with the need for respite, though towards the lower pole of this value range according to the cut-off criterion [3]. RSA values fell in the high resilience range, though close to the boundary with the mid-level. SWLS values did not differ from those reported by Italian samples derived from the general population [24]. SF-36 subscales' values were aligned with the Italian norm [26]. 
Spearman correlations were calculated between the scores of AC-QoL and the other measures. While AC-QoL investigates positive and negative caring dimensions, the other measures assess only one pole of psychological functioning. It was therefore possible to explore both convergence and divergence between the positive and negative facets of ACQoL and the measures of burden (CBI), resilience (RSA) and global well-being and health (SWLS and SF-36 subscales). Overall, as illustrated in Table 8, significant correlations were detected between AC-QoL and the other measures.

\section{---- TABLE 8 ABOUT HERE ----}

A moderately negative correlation emerged between Caregiver Burden Inventory and ACQoL total score. In addition, CBI score was negatively correlated with the burden-related subscales of caring choice and stress. All the correlations between Resilience Scale for Adults and AC-QoL scores were negative, as high resilience levels correspond to low RSA scores. In particular, resilience was correlated with AC-QoL total score, perceived support, caring choice, caring stress, and to a lesser extent with personal growth, money matters, sense of value, and carer satisfaction. The Satisfaction With Life Scale showed positive correlations with AC-QoL total score, caring choice, caring stress, perceived support and carer satisfaction. As for SF-36 subscales, no relevant correlations were detected between physical health and AC-QoL scores, while Mental Health was positively correlated with ACQoL total score, caring stress, caring choice and carer satisfaction.

Finally, as shown in Table 9, correlations between Ac-QoL scores and sample demographic features did not exceed .30 , being thus below the threshold deemed as acceptable to infer association. 


\section{Discussion}

Two aims were pursued through this study. The first one was to investigate the psychometric properties of the Italian version of AC-QoL among parents of children diagnosed with disabling diseases. The second aim was to evaluate, for the first time at the international level, the convergent and discriminant validity of AC-QoL with measures of burden, resilience, health and well-being.

In order to achieve the first aim, we examined the AC-QoL factor structure adopting a split sample approach. Two solutions identified by exploratory factor analysis on subsample 1, including 7 and 8 factors respectively, showed good fit indices and were thus further investigated. The 8-factor solution, replicating the original AC-QoL structure, proved to be more adequate. All items showed the highest loadings on the expected factor, except for items 37 and 38, included in carer satisfaction but showing higher loadings on caring stress. Confirmatory factor analysis performed on subsample 2 further corroborated the 8 factor model adequacy.

Although moderate to high correlations were detected among factors, only carer satisfaction was significantly correlated with six factors out of seven. This finding can be related to the conceptual broadness of the term "satisfaction", currently used across disciplines as a global measure of well-being, in its general formulation of satisfaction with life [36]. Several studies identified positive correlations between life satisfaction and other dimensions of positive functioning, such as personal growth, self-determination and selfefficacy [12,37-39]. Although referring to the caring context, the positive correlations detected in the present study between satisfaction and the other positive facets of psychological functioning (sense of value, abilities and personal growth), as well as the correlation between satisfaction and caring choice (whose items are conceptually related to self-determination) are consistent with the well-being literature. Finally, the positive 
correlation between carer satisfaction and support for caring is consistent with the role of social relationships in promoting well-being among parents of children with disabilities [40].

The peculiar loading pattern of item 37 and 38, included in carer satisfaction, can be related to their negative formulation. Both items refer to feelings of discomfort and disappointment, more aligned with the negative experiences described within the stress dimension than with the positive ones captured by satisfaction. Moreover, the positive loadings of these negatively worded items on caring stress contrast with the negligible loadings on the same factor of the other three (and positively worded) items included in carer satisfaction. From a broader perspective, this opposite pattern points to the importance of distinguishing between conceptualizations of well-being as absence of negative symptoms or as presence of positive indicators.

Also the positive correlation detected between support for caring and the burden related dimensions of caring choice and stress is consistent with the caregiving and wellbeing literature. As concerns parents of children with disabilities, supportive relationships were shown to counterbalance caring strain and constraints, allowing caregivers to express and share feelings, enjoy free time and engage in self-determined activities [41,42]. In the well-being literature, positive relations and connectedness represent core dimensions in a variety of models of positive functioning, such as psychological well-being [43], the dual continua model of mental health [44] and self-determination [37]. In the bio-psycho-social model endorsed by the International Classification of Functioning [45], relational and social resources represent key facilitators for promoting individuals' optimal functioning [46].

The positive correlation detected between caring abilities and sense of value (referring to the appreciation expressions received from the care recipient) is specifically consistent with the construct of psychological well-being, encompassing the dimensions of 
mastery, positive relations and self-acceptance $[43,47]$. Moreover, it highlights the contribution of children's positive feedback to parents' self-efficacy and self-esteem [48].

As for AC-QoL reliability, Cronbach's alpha values for subscales and total score were more than adequate. Only items 18, 37 and 38 showed particularly low levels of correlation with other elements of the same subscale; in spite of these results, corrected itemscale correlation values confirmed the good levels of internal consistency for the AC-QoL Italian translation.

As concerns the second aim of the study, AC-QoL showed good convergent validity with burden and resilience measures, through an overall moderate and negative correlation with the total scores of Caregiver Burden Inventory and Resilience Scale for Adults (as low RSA scores correspond to high levels of resilience). At the subscale level, in line with the theoretical expectations CBI was correlated with caring stress and choice. RSA showed low to moderate correlations with most AC-QoL subscales, in particular those referring to personal and environmental resources, including the important asset of money matters [17]. Overall, these findings support the definition of resilience as the successful adjustment to adversarial conditions.

AC-QoL showed discriminant validity with perceived physical health, measured through the Role Limitations due to Physical Problems subscale of SF-36. RLP was uncorrelated with both total and subscales scores of AC-QoL, corroborating the view of health as a bio-psycho-social construct encompassing dimensions that differently contribute to personal functioning, without being necessarily intercorrelated [46,49]. Within the specific context under study, the benefits derived from caregiving in terms of personal growth, self-esteem, and satisfaction seem to co-exist with physical burden components. The correlation pattern of AC-QoL with Satisfaction With Life Scale and Mental Health subscale of SF-36, representing general measures of mental well-being, requires a 
more articulated analysis. While SWLS and MH scores were low to moderately correlated with AC-QoL total score, their correlations with the subscales referring to personal and social resources were overall fewer and lower, compared with those detected between these subscales and the Resilience Scale for Adults. These findings suggest that caregivers' quality of life, as assessed through the AC-QoL, is conceptually closer to resilience than to the broader and less specific constructs of life satisfaction and mental health. This is particularly true of positive AC-QoL dimensions such as personal growth and sense of value, often investigated in contexts of adversity, trauma and disease $[47,50]$. Therefore, these results can be interpreted as an evidence of discriminant validity of specific AC-QoL subscales vis-à-vis general well-being measures. Based on this reasoning, the similarity of RSA, SWLS and MH correlation patterns with the burden related subscales of stress and choice seems apparently contradictory. However, the overarching conceptual juxtaposition between well-being and ill-being may make commonalities among different well-being dimensions more relevant than discrepancies, when evaluating their overall relationship with ill-being dimensions. These results can thus be interpreted as an evidence of convergent validity between AC-QoL ill-being related subscales and both general and specific measures of well-being.

Finally, the study findings can be discussed in light of the sample features. In line with previous studies, no relationship was detected between AC-QoL scores and participants' demographics, while the lack of correlations with child disease severity diverged from the literature. Participants reported an overall high quality of life, especially as concerns sense of value. This finding can be related to their twofold role as parents and caregivers, entailing educational and child raising responsibilities. Participants did not differ from the general population as concerns global well-being measures; moreover, they reported high levels of resilience, at the same time acknowledging caring related challenges and difficulties through perceived burden levels compatible with the need for respite. 
Overall, these findings confirm the co-existence of personal and relational resources with the negative aspects of family caregiving, and their contribution to caregivers' perception of an overall high quality of life.

\section{Strengths and limitations}

To the best of our knowledge, this is the first study investigating the convergent and discriminant validity of the AC-QoL with burden and well-being measures. The findings highlight the usefulness of jointly evaluating ill- and well-being dimensions of caregivers' quality of life through a systemic approach that takes into account both psychological and environmental components. This is also the first validation study of AC-QoL in the Italian context.

This study has some limitations as well. Participants were parents, therefore results cannot be generalized to caregivers of spouses or older family members. Moreover, data were collected in centers affiliated to a single institution, thus homogeneous in terms of service typology and quality. In addition, the study lacks of a test-retest reliability check.

\section{Conclusions}

The family dimension of healthcare represents a primary policy issue. The inclusion of family caregivers' quality of life measures in the evaluation protocols of children with disabilities enrolled in rehabilitation programs can have far-reaching implications for patients' and family health, adherence to rehabilitation programs, and quality of life. In addition, from the ICF perspective the assessment and monitoring of caregivers' needs and assets represents a substantial source of information for healthcare systems and communities as a whole. Information on these dimensions may guide interventions aimed at reducing caregivers' exposure to burnout risk, increasing their resilience, and promoting patients' and 
families' successful social adjustment. Therefore, parsimonious and comprehensive assessment instruments such as AC-QoL could be useful for researchers and practitioners, healthcare services and community institutions.

\section{Acknowledgements}

This study was made possible by the engagement and dedication of many people. The authors would like to express their gratitude to the directors of all the rehabilitation centers who recruited the participants; psychologists and social workers who helped in data collection, and family caregivers who provided their invaluable contribution to the study.

\section{Declaration of interest}

The authors declare that the research was conducted in the absence of any commercial or financial relationships that could be construed as a potential conflict of interest. 


\section{References}

[1] Feinberg L, Reinhard SC, Houser A, Choula R. Valuing the invaluable: 2011 Update. The growing contributions and costs of family caregiving. Washington DC: AARP Public Policy Institute; 2009.

[2] Giardini A, Ferrari P, Negri EM, et al. The positive role of caregivers in terminal cancer patients' abilities: usefulness of the ICF framework. Eur J Phys Rehab Med 2016;52:214-222.

[3] Novak M, Guest C. Application of a multidimensional caregiver burden inventory. Gerontologist. 1989;29:798-803.

[4] Brannan AM, Heflinger CA. Distinguishing caregiver strain from psychological distress: modeling the relationships among child, family, and caregiver variables. J Child Fam Stud. 2001;10:405-18.

[5] Brannan AM, Heflinger CA. Caregiver, child, family, and service system contributors to caregiver strain in two child mental health service systems. J Behav Health Serv Res. 2006;33:408-22.

[6] Family Caregiver Alliance, Benjamin Rose Institute of Aging \& The Margaret Blenker Research Institute. Selected caregiver assessment measures: A resource inventory for practitioners. San Francisco (CA): Family Caregiver Alliance; 2012.

[7] Montes G, Halterman JS. Psychological functioning and coping among mothers of children with autism: a population-based study. Pediatrics. 2007;119:e1040-6.

[8] Olsson MB, Larsman P, Hwang PC. Relationships among risk, sense of coherence, and well-being in parents of children with and without intellectual disabilities. $\mathbf{J}$ Policy Pract Intellect Disabil. 2008;5:227-36.

[9] Emerson E, McCulloch A, Graham H, et al. Socioeconomic circumstances and risk of psychiatric disorders among parents of children with early cognitive delay. Am J Intellect Dev Disabil. 2010;115:30-42.

[10] MacDonald EE, Hastings RP, Fitzsimons E. Psychological acceptance mediates the impact of the behaviour problems of children with intellectual disability on fathers' psychological adjustment. J Appl Res Intellect Disabil. 2010;23:27-37.

[11] Munsell EP, Kilmer RP, Cook JR, et al. The effects of caregiver social connections on caregiver, child, and family well-being. Am J Orthopsychiatry. 2012;82:137-45. 
[12] Magliano L, Patalano M, Sagliocchi A, et al. "I have got something positive out of this situation": psychological benefits of caregiving in relatives of young people with muscular dystrophy. J Neurol. 2014;261:188-95.

[13] Delle Fave A, Fianco A, Sartori RDG. Psychological and relational resources in the experience of disability and caregiving. In: Joseph S, editor. Positive psychology in practice. Hoboken (NJ): John Wiley \& Sons, Inc; 2015. p. 615-33.

[14] Bonanno GA. Loss, trauma, and human resilience: have we underestimated the human capacity to thrive after extremely aversive events? Am Psychol. 2004;59:208.

[15] Walsh F. Family resilience: a framework for clinical practice. Fam Process. 2003;42:1-18.

[16] Gerstein ED, Crnic KA, Blacher J, et al. Resilience and the course of daily parenting stress in families of young children with intellectual disabilities. J Intellect Disabil Res. 2009;53:981-97.

[17] McConnell D, Savage A, Breitkreuz R. Resilience in families raising children with disabilities and behavior problems. Res Dev Disabil. 2014;35:833-48.

[18] Fianco A, Sartori RDG, Negri L, et al. The relationship between burden and wellbeing among caregivers of Italian people diagnosed with severe neuromotor and cognitive disorders. Res Dev Disabil. 2015;39:43-54.

[19] Joseph S, Becker S, Elwick H, et al. Adult Carers Quality of Life questionnaire (AC- QoL): development of an evidence- based tool. Mental Health Rev J. 2012;17:57-69.

[20] Marvardi M, Mattioli P, Spazzafumo L, et al. The Caregiver Burden Inventory in evaluating the burden of caregivers of elderly demented patients: results from a multicenter study. Aging Clin Experim Res. 2005; 17:46-53.

[21] Friborg $\mathrm{O}$, Hjemdal $\mathrm{O}$, Rosenvinge $\mathrm{JH}$, et al. A new rating scale for adult resilience: what are the central protective resources behind healthy adjustment? Int J Methods in Psych Res. 2003;12:65-76.

[22] Peveri L. Resilienza e regolazione delle emozioni. Un approccio multimodale [Resilience and emotion regulation. A multimodal approach] [dissertation]. Milano (Italy): Università degli Studi di Milano Bicocca; 2009. Italian.

[23] Diener E, Emmons RA, Larsen RJ, et al. The Satisfaction With Life Scale. J Pers Assessment. 1985;49:71-5. 
[24] Goldwurm GF, Baruffi M, Colombo F. Qualità della vita e benessere psicologico. Aspetti comportamentali e cognitivi del vivere felice. [Quality of life and psychological well-being. Behavioural and cognitive facets of an happy life]. Milano (Italy): McGraw-Hill Companies; 2004. Italian.

[25] Ware JE. SF-36 health survey: Manual and interpretation guide. Boston (MA): Health Institute, New England Medical Centre; 1993.

[26] Apolone G, Mosconi P, Ware J Jr. Questionario sullo stato di salute SF-36. Manuale d'uso e guida all'interpretazione dei risultati [Questionnaire on the health state SF-36. Manual and guide to interpretation of results]. Milano (Italy): Guerini e Associati; 2000. Italian.

[27] Beauducel A, Herzberg PY. On the performance of maximum likelihood versus means and variance adjusted weighted least squares estimation in CFA. Struct Equat Model. 2006;13:186-203.

[28] Hu L-T, Bentler PM. Evaluating model fit. In: Hoyle RH, editor. Structural equation modeling: concepts, issues, and applications. Thousand Oaks (CA): Sage Publications, Inc; 1995. p. 76-99.

[29] Hu L, Bentler PM. Cutoff criteria for fit indexes in covariance structure analysis: conventional criteria versus new alternatives. Struct Equat Model. 1999; 6:1-55.

[30] Meulman JJ, Van Der Kooij AJ, Heiser WJ. Principal components analysis with nonlinear optimal scaling transformations for ordinal and nominal data. In Kaplan D, editor. The Sage handbook of quantitative methodology for the social sciences. Thousand Oaks (CA): Sage; 2004, p. 49-70.

[31] Hinkle DE, Wiersma W, Jurs SG. Applied Statistics for the Behavioral Sciences. Boston (MA): Houghton Mifflin; 2003.

[32] World Health Organization. International statistical classification of diseases and related health problems. 10th ed. Geneva (Switzerland): World Health Organization; 2010.

[33] Hutcheson GD, Sofroniou N. The multivariate social scientist: introductory statistics using generalized linear models. London (United Kingdom): SAGE; 1999.

[34] van Driel OP. On various causes of improper solutions in maximum likelihood factor analysis. Psychometrika. 1978;43:225-43.

[35] Nunnally JC, Bernstein IH. Psychometric theory. New York (NY): McGraw-Hill; 1994. 
[36] Diener E. Subjective well-being. The science of happiness and a proposal for a national index. Am Psychol. 2000;55:34-43.

[37] Ryan RM, Deci EL. Self-determination theory and the facilitation of intrinsic motivation, social development, and well-being. Am Psychol. 2000;55:68-78.

[38] Keyes CLM, Shmotkin D, Ryff CD. Optimizing well-being: The empirical encounter of two traditions. J Pers Soc Psychol 2002;82:1007-1022.

[39] Bassi M, Falautano M, Cilia S, et al. The coexistence of well- and ill-being in persons with multiple sclerosis, their caregivers and health professionals. J Neurol Sci. 2014;337:67-73.

[40] White N, Hastings RP. Social and professional support for parents of adolescents with severe intellectual disabilities. J Appl Res Intellect Disabil. 2004;17:181-190.

[41] Mausbach BT, Harmell AL, Moore RC, et al. Influence of caregiver burden on the association between daily fluctuations in pleasant activities and mood: a daily diary analysis. Behav Res Ther. 2011;49:74-9.

[42] Cramm JM, Nieboer AP. Longitudinal study of parents' impact on quality of life of children and young adults with intellectual disabilities. J Appl Res Intellect Disabil. 2012;25:20-8.

[43] Ryff CD. Happiness is everything, or is it? Explorations on the meaning of psychological well-being. J Pers Soc Psychol. 1989;57:1069-1081.

[44] Keyes CLM. Promoting and protecting mental health as flourishing: a complementary strategy for improving national mental health. Am Psychol. 2007;62:95-108.

[45] World Health Organization. International Classification of Functioning, Disability and Health (ICF). Geneva (Switzerland): World Health Organization; 2001.

[46] Stucki G, Zampolini M, Juocevicius A, et al. Practice, science and governance in interaction: European effort for the system-wide implementation of the International Classification of Functioning, Disability and Health (ICF) in Physical and Rehabilitation Medicine. Eur J Phys Rehab Med 2016 [Nov 24]; [9].

URL:http://www.minervamedica.it/en/journals/europamedicophysica/article.php?cod=R33Y9999N00A16112401

[47] Ryff CD. Psychological well-being revisited: advances in the science and practice of eudaimonia. Psychother Psychosom. 2014:83:10-28. 
[48] Steca P, Bassi M, Caprara GV, et al. Parents' self-efficacy beliefs and their children's psychosocial adaptation during adolescence. J Youth Adolesc. 2011;40:320-31.

[49] World Health Organization. Mental health: New understanding, new hope. Report of the World Health Organization. Geneva (Switzerland): World Health Organization; 2001.

[50] Tedeschi RG, Calhoun LG. A clinical approach to posttraumatic growth. In: Linley PA, Joseph S, editors. Positive psychology in practice. Hoboken (NJ): John Wiley \& Sons Inc; 2004. p. 405-19. 
Table 1. Participants' demographic characteristics.

\begin{tabular}{l|lll}
\hline Participants $(N=591)$ & $\mathrm{n}(\%)$ & $\mathrm{M}(\mathrm{SD})$ & $\operatorname{Mdn}_{\left(25^{\text {th }} / 75^{\text {th }}\right)^{\mathrm{a}}}$ \\
\hline Age & $527(89)$ & & \\
Gender (Female) & & & \\
Education $^{\mathrm{b}}$ & $187(32)$ & & \\
$\quad$ Below High School & $387(65)$ & & \\
$\quad$ High School or higher & $364(62)$ & & \\
Employed $^{\mathrm{c}}$ & & & \\
Marital Status $^{\mathrm{d}}$ & $534(90)$ & & \\
$\quad$ Married / Cohabiting & $11(2)$ & & \\
$\quad$ Single & $38(6)$ & & \\
$\quad$ Divorced & $4(1)$ & & \\
$\quad$ Widowed & & & \\
Child Age & & & \\
Child Disease Severity & $332(56)$ & & \\
$\quad$ Low-mild & $259(44)$ & & \\
$\quad$ High & &
\end{tabular}

Note. N: number of participants;

${ }^{a}$ Centiles.

${ }^{\mathrm{b}}$ Education was dichotomised into: "Below High School" which comprises elementary school and middle school; "High School or higher" which includes high school, university degree, $\mathrm{PhD}$, and also medical specialty for physicians; 17 participants (3\%) did not provide this information;

${ }^{c} 5$ participants (1\%) did not provide this information;

${ }^{\mathrm{d}} 4$ participants(1\%) did not provide this information. 
Table 2. Descriptive statistics of AC-QoL items.

\begin{tabular}{|c|c|c|c|c|c|c|c|}
\hline $\begin{array}{l}\mathrm{N}=591 \\
\text { Item }\end{array}$ & $\begin{array}{l}\text { Min } \\
\text { Max }\end{array}$ & $\begin{array}{c}\mathrm{M} \\
(\mathrm{SD})\end{array}$ & $\begin{array}{l}\text { Mdn } \\
{[\mathrm{IQR}]}\end{array}$ & Item & $\begin{array}{l}\text { Min } \\
\text { Max }\end{array}$ & $\begin{array}{c}\mathrm{M} \\
(\mathrm{SD})\end{array}$ & $\begin{array}{l}\text { Mdn } \\
\text { [IQR] }\end{array}$ \\
\hline 1. Emotional support & $0-3$ & $1.71(0.79)$ & $2[1]$ & 21. Tolerance & $0-3$ & $1.87(0.80)$ & $2[1]$ \\
\hline 2. Attention to needs & $0-3$ & $1.85(0.85)$ & $2[1]$ & 22. Personal learning & $0-3$ & $2.13(0.74)$ & $2[1]$ \\
\hline 3. Professional support & $0-3$ & $1.97(0.80)$ & $2[2]$ & 23. Personal growth & $0-3$ & $2.24(0.73)$ & $2[1]$ \\
\hline 4. Help / information & $0-3$ & $2.01(0.74)$ & $2[1]$ & 24. Positive things & $0-3$ & $2.02(0.78)$ & $2[1]$ \\
\hline 5. Practical support & $0-3$ & $1.75(0.84)$ & $2[1]$ & 25. Better person & $0-3$ & $2.08(0.83)$ & $2[2]$ \\
\hline 6. Life on hold (R) & $0-3$ & $2.38(0.71)$ & $3[1]$ & 26. To feel valued & $0-3$ & $2.69(0.60)$ & $3[0]$ \\
\hline 7. Social constraints $(\mathrm{R})$ & $0-3$ & $2.27(0.80)$ & $2[1]$ & 27. To feel respected & $0-3$ & $2.39(0.75)$ & $3[1]$ \\
\hline 8. Low future choice $(\mathrm{R})$ & $0-3$ & $2.14(0.86)$ & $2[1]$ & 28. To feel appreciated & $0-3$ & $2.38(0.78)$ & $3[1]$ \\
\hline 9. No control $(\mathrm{R})$ & $0-3$ & $2.39(0.78)$ & $3[1]$ & 29. To feel rewarded & $0-3$ & $2.59(0.65)$ & $3[1]$ \\
\hline 10. Action constraints (R) & $0-3$ & $2.11(0.79)$ & $2[1]$ & 30. Good relationship & $0-3$ & $2.62(0.60)$ & $3[1]$ \\
\hline 11. Depressed (R) & $0-3$ & $2.47(0.62)$ & $3[1]$ & 31. Good performance & $0-3$ & $2.18(0.65)$ & $2[1]$ \\
\hline 12. Worn out $(\mathrm{R})$ & $0-3$ & $2.25(0.69)$ & $2[1]$ & 32. Caring for needs & $1-3$ & $2.46(0.60)$ & $3[1]$ \\
\hline 13. Mentally exhausted (R) & $0-3$ & $2.44(0.71)$ & $3[1]$ & 33. Care recipient QoL & $1-3$ & $2.29(0.69)$ & $2[1]$ \\
\hline 14. Physically exhausted (R) & $0-3$ & $2.29(0.74)$ & $2[1]$ & 34. Caring management & $1-3$ & $2.29(0.66)$ & $2[1]$ \\
\hline 15. Stressed (R) & $0-3$ & $2.19(0.72)$ & $2[1]$ & 35. Effective coping & $0-3$ & $2.08(0.70)$ & $2[1]$ \\
\hline 16. Debt concerns (R) & $0-3$ & $2.03(0.89)$ & $2[1]$ & 36. Importance & $0-3$ & $2.18(0.84)$ & $2[1]$ \\
\hline 17. Financial satisfaction & $0-3$ & $1.47(0.92)$ & $2[1]$ & 37. Resentment (R) & $0-3$ & $2.49(0.66)$ & $3[1]$ \\
\hline 18. Savings & $0-3$ & $1.21(0.95)$ & $1[2]$ & 38. Frustration $(\mathrm{R})$ & $0-3$ & $2.70(0.56)$ & $3[1]$ \\
\hline 19. Money worries (R) & $0-3$ & $1.61(0.87)$ & $2[1]$ & 39. Enjoyment & $0-3$ & $1.74(0.99)$ & $2[2]$ \\
\hline 20. Needs coverage & $0-3$ & $1.96(0.89)$ & $2[2]$ & 40. Caring satisfaction & $0-3$ & $2.07(0.85)$ & $2[1]$ \\
\hline
\end{tabular}

Note. N: number of participants; M: mean; SD: standard deviation; Mdn: median; IQR: interquartile range; (R): reverse coded item. 
Table 3. Exploratory Factor Analysis, subsample 1: oblimin-rotated factor loadings.

\begin{tabular}{|c|c|c|c|c|c|c|c|}
\hline $\begin{array}{l}\mathrm{N}=296 \\
\text { Item }\end{array}$ & Support & Choice & Stress & Money Growth & Value & Ability & Satisfaction \\
\hline 1. Emotional support & .53 & .27 & & & .24 & & \\
\hline 2. Attention to needs & .78 & & & & & & \\
\hline 3. Professional support & .91 & & & & & & \\
\hline 4. Help / information & .79 & & & & & & \\
\hline 5. Practical support & .71 & & & & & & \\
\hline 6. Life on hold (R) & & .60 & .21 & & & & \\
\hline 7. Social constraints (R) & & .75 & & & & & \\
\hline 8. Low future choice $(\mathrm{R})$ & & .82 & & & & & \\
\hline 9. No control (R) & & .55 & .20 & & & & \\
\hline 10. Action constraints (R) & & .62 & .28 & & & & \\
\hline 11. Depressed (R) & & & .67 & & & & \\
\hline 12. Worn out (R) & & & .90 & & & & \\
\hline 13. Mentally exhausted (R) & & & .83 & & & & \\
\hline 14. Physically exhausted (R) & & & .86 & & & & \\
\hline 15. Stressed (R) & & & .74 & & & & \\
\hline 16. Debt concerns (R) & & .24 & & .64 & & & \\
\hline 17. Financial satisfaction & & & & .94 & & & \\
\hline 18. Savings & & & & .54 & & & \\
\hline 19. Money worries (R) & & & & .60 & & & \\
\hline 20. Needs coverage & & & & .73 & & & \\
\hline
\end{tabular}

Note. N: number of participants; Bold: item highest factor loading; (R): reverse coded item; Loadings below .20 are not showed; Support: support for caring; Choice: caring choice; Stress: caring stress; Money: money matters;

Growth: personal growth; Value: sense of value; Ability: ability to care; Satisfaction: carer satisfaction. 
Table 3. Continued

\begin{tabular}{|c|c|c|c|c|c|c|c|c|}
\hline $\begin{array}{l}\mathrm{N}=296 \\
\text { Item }\end{array}$ & Support & Choice & Stress & Money & Growth & Value & Ability & Satisfaction \\
\hline 21. Tolerance & & & & & .58 & & & \\
\hline 22. Personal learning & & & & & .89 & & & \\
\hline 23. Personal growth & & & & & 1.02 & & & \\
\hline 24. Positive things & & & .22 & & .66 & & & \\
\hline 25. Better person & & & & & .80 & & & \\
\hline 26. To feel valued & & & & & & .89 & & \\
\hline 27. To feel respected & & & & & & .95 & & \\
\hline 28. To feel appreciated & & & & & & .84 & & \\
\hline 29. To feel rewarded & & & & & & .88 & & \\
\hline 30. Good relationship & & & & & & .82 & & \\
\hline 31. Good performance & & & & & & & .61 & \\
\hline 32. Caring for needs & & & & & & & .81 & \\
\hline 33. Care recipient QoL & & & & & & & .73 & \\
\hline 34. Caring management & & & & & & & .84 & \\
\hline 35. Effective coping & & & & & & & .77 & \\
\hline 36. Importance & & & & & & & & .71 \\
\hline 37. Resentment (R) & & .21 & .46 & & & & & .31 \\
\hline 38. Frustration (R) & -.20 & & .37 & & -.22 & .28 & & .35 \\
\hline 39. Enjoyment & & & & & & & & .75 \\
\hline 40. Caring satisfaction & & & & & & & & .59 \\
\hline
\end{tabular}

Note. N: number of participants; Bold: item highest factor loading; (R): reverse coded item; Loadings below .20 are not showed; Support: support for caring; Choice: caring choice; Stress: caring stress; Money: money matters; Growth: personal growth; Value: sense of value; Ability: ability to care; Satisfaction: carer satisfaction. 
Table 4. Confirmatory Factor Analysis, subsample 2: standardized factor loadings.

\begin{tabular}{|c|c|c|c|c|c|c|c|c|c|}
\hline $\begin{array}{l}\mathrm{N}=295 \\
\text { Item }\end{array}$ & Support & Choice & Stress & Money & Item & Growth & Value & Ability & Satisfaction \\
\hline 1. Emotional support & .70 & & & & 21. Tolerance & .59 & & & \\
\hline 2. Attention to needs & .82 & & & & 22. Personal learning & .84 & & & \\
\hline 3. Professional support & .87 & & & & 23. Personal growth & .89 & & & \\
\hline 4. Help / information & .87 & & & & 24. Positive things & .87 & & & \\
\hline 5. Practical support & .85 & & & & 25. Better person & .89 & & & \\
\hline 6. Life on hold (R) & & .92 & & & 26. To feel valued & & .80 & & \\
\hline 7. Social constraints $(\mathrm{R})$ & & .85 & & & 27. To feel respected & & .81 & & \\
\hline 8. Low future choice $(\mathrm{R})$ & & .86 & & & 28. To feel appreciated & & .91 & & \\
\hline 9. No control (R) & & .81 & & & 29. To feel rewarded & & .91 & & \\
\hline 10. Action constraints $(\mathrm{R})$ & & .87 & & & 30. Good relationship & & .85 & & \\
\hline 11. Depressed (R) & & & .86 & & 31. Good performance & & & .90 & \\
\hline 12. Worn out $(\mathrm{R})$ & & & .84 & & 32. Caring for needs & & & .82 & \\
\hline 13. Mentally exhausted (R) & & & .87 & & 33. Care recipient QoL & & & .83 & \\
\hline 14. Physically exhausted (R) & & & .79 & & 34. Caring management & & & .81 & \\
\hline 15. Stressed (R) & & & .91 & & 35. Effective coping & & & .67 & \\
\hline 16. Debt concerns $(\mathrm{R})$ & & & & .78 & 36. Importance & & & & .66 \\
\hline 17. Financial satisfaction & & & & .77 & 37. Resentment (R) & & & & .69 \\
\hline 18. Savings & & & & .65 & 38. Frustration $(\mathrm{R})$ & & & & .74 \\
\hline 19. Money worries (R) & & & & .59 & 39. Enjoyment & & & & .76 \\
\hline 20. Needs coverage & & & & .70 & 40. Caring satisfaction & & & & .87 \\
\hline
\end{tabular}

Note. N: number of participants. 
Table 5. Confirmatory Factor analysis, subsample 2: factor correlations.

\begin{tabular}{|c|c|c|c|c|c|c|c|c|}
\hline $\mathrm{N}=295$ & 1. & 2. & 3. & 4. & 5. & 6. & 7. & 8. \\
\hline 1. Support & - & & & & & & & \\
\hline 2. Choice & .60 & - & & & & & & \\
\hline 3. Stress & .56 & .81 & - & & & & & \\
\hline 4. Money & .29 & .28 & .29 & - & & & & \\
\hline 5. Growth & .37 & .30 & .26 & .17 & - & & & \\
\hline 6. Value & .39 & .36 & .45 & .03 & .43 & - & & \\
\hline 7. Ability & .41 & .19 & .32 & .17 & .44 & .69 & - & \\
\hline 8. Satisfaction & .57 & .61 & .71 & .18 & .55 & .77 & .63 & - \\
\hline
\end{tabular}

Note. N: number of participants. 
Table 6. Corrected item-scale correlation and Cronbach's alpha coefficients in the whole sample.

\begin{tabular}{|c|c|c|c|c|c|c|c|c|}
\hline $\begin{array}{l}\mathrm{N}=591 \\
\text { Item }\end{array}$ & $\begin{array}{c}\text { Support } \\
\alpha=.87\end{array}$ & $\begin{array}{l}\text { Choice } \\
\alpha=.89\end{array}$ & $\begin{array}{l}\text { Stress } \\
\alpha=.89\end{array}$ & $\begin{array}{l}\text { Money } \\
\alpha=.79\end{array}$ & $\begin{array}{c}\text { Growth } \\
\alpha=.89\end{array}$ & $\begin{array}{l}\text { Value } \\
\alpha=.90\end{array}$ & $\begin{array}{l}\text { Ability } \\
\alpha=.85\end{array}$ & $\begin{array}{c}\text { Satisfaction } \\
\alpha=.79\end{array}$ \\
\hline 1. Emotional support & .60 & & & & & & & \\
\hline 2. Attention to needs & .74 & & & & & & & \\
\hline 3. Professional support & .80 & & & & & & & \\
\hline 4. Help / information & .77 & & & & & & & \\
\hline 5. Practical support & .76 & & & & & & & \\
\hline 6. Life on hold (R) & & .78 & & & & & & \\
\hline 7. Social constraints (R) & & .77 & & & & & & \\
\hline 8. Low future choice $(\mathrm{R})$ & & .80 & & & & & & \\
\hline 9. No control (R) & & .66 & & & & & & \\
\hline 10. Action constraints $(\mathrm{R})$ & & .77 & & & & & & \\
\hline 11. Depressed (R) & & & .70 & & & & & \\
\hline 12. Worn out (R) & & & .79 & & & & & \\
\hline 13. Mentally exhausted (R) & & & .80 & & & & & \\
\hline 14. Physically exhausted (R) & & & .73 & & & & & \\
\hline 15. Stressed (R) & & & .82 & & & & & \\
\hline 16. Debt concerns $(\mathrm{R})$ & & & & .63 & & & & \\
\hline 17. Financial satisfaction & & & & .71 & & & & \\
\hline 18. Savings & & & & .51 & & & & \\
\hline 19. Money worries (R) & & & & .53 & & & & \\
\hline 20. Needs coverage & & & & .56 & & & & \\
\hline
\end{tabular}

Note. N: number of participants; (R): reverse coded item; $\alpha$ : Cronbach's alpha coefficient. 
Table 6. Continued

\begin{tabular}{|c|c|c|c|c|c|c|c|c|}
\hline $\begin{array}{l}\mathrm{N}=591 \\
\text { Item }\end{array}$ & $\begin{array}{c}\text { Support } \\
\alpha=.87\end{array}$ & $\begin{array}{c}\text { Choice } \\
\alpha=.89\end{array}$ & $\begin{array}{l}\text { Stress } \\
\alpha=.89\end{array}$ & $\begin{array}{l}\text { Money } \\
\alpha=.79\end{array}$ & $\begin{array}{c}\text { Growth } \\
\alpha=.89\end{array}$ & $\begin{array}{l}\text { Value } \\
\alpha=.90\end{array}$ & $\begin{array}{l}\text { Ability } \\
\alpha=.85\end{array}$ & $\begin{array}{c}\text { Satisfaction } \\
\alpha=.79\end{array}$ \\
\hline 21. Tolerance & & & & & .60 & & & \\
\hline 22. Personal learning & & & & & .81 & & & \\
\hline 23. Personal growth & & & & & .85 & & & \\
\hline 24. Positive things & & & & & .70 & & & \\
\hline 25. Better person & & & & & .83 & & & \\
\hline 26. To feel valued & & & & & & .75 & & \\
\hline 27. To feel respected & & & & & & .75 & & \\
\hline 28. To feel appreciated & & & & & & .74 & & \\
\hline 29. To feel rewarded & & & & & & .80 & & \\
\hline 30. Good relationship & & & & & & .76 & & \\
\hline 31. Good performance & & & & & & & .62 & \\
\hline 32. Caring for needs & & & & & & & .78 & \\
\hline 33. Care recipient QoL & & & & & & & .77 & \\
\hline 34. Caring management & & & & & & & .76 & \\
\hline 35. Effective coping & & & & & & & .65 & \\
\hline 36. Importance & & & & & & & & .62 \\
\hline 37. Resentment (R) & & & & & & & & .46 \\
\hline 38. Frustration (R) & & & & & & & & .53 \\
\hline 39. Enjoyment & & & & & & & & .68 \\
\hline 40. Caring satisfaction & & & & & & & & .72 \\
\hline
\end{tabular}

Note. N: number of participants; (R): reverse coded item; $\alpha$ : Cronbach's alpha coefficient. 
Table 7. Descriptive statistics of all the study measures.

\begin{tabular}{lll}
\hline $\mathrm{N}=591$ & $\mathrm{M}(\mathrm{SD})$ & $\mathrm{Mdn}[\mathrm{IQR}]$ \\
\hline Support & $9.27(3.24)$ & $9[5]$ \\
Choice & $11.28(3.28)$ & $12[4]$ \\
Stress & $11.64(2.88)$ & $12[4]$ \\
Money & $8.27(3.28)$ & $8[5]$ \\
Growth & $10.34(3.19)$ & $10[5]$ \\
Value & $12.67(2.84)$ & $14[4]$ \\
Ability & $11.30(2.60)$ & $11[4]$ \\
Satisfaction & $11.16(2.86)$ & $11[5]$ \\
AC-QoL total & $85.94(15.28)$ & $87[21]$ \\
Caregiver Burden Inventory & $24.92(16.04)$ & $22[21]$ \\
Resilience Scale for Adults & $74.58(17.94)$ & $74[28]$ \\
Satisfaction With Life Scale & $22.95(7.13)$ & $24[10]$ \\
Role Limitations due to Physical Problems & $76.6(34.10)$ & $100[50]$ \\
General Mental Health & $63.95(17.92)$ & $64[24]$ \\
\hline
\end{tabular}

Note. N: number of participants; AC-QoL total: AC-QoL total score; 
Table 8. Spearman's correlations between AC-QoL dimensions and the other measures.

\begin{tabular}{lccccc}
\hline N=591 & $\begin{array}{c}\text { Caregiver Burden } \\
\text { Inventory }\end{array}$ & $\begin{array}{c}\text { Resilience Scale } \\
\text { for Adults }\end{array}$ & $\begin{array}{c}\text { Satisfaction } \\
\text { With Life Scale }\end{array}$ & $\begin{array}{c}\text { Role Limitations due } \\
\text { to Physical Problems }\end{array}$ & $\begin{array}{c}\text { General Mental } \\
\text { Health }\end{array}$ \\
\hline Support & -.37 & -.47 & .37 & .19 & .30 \\
Choice & -.70 & -.43 & .49 & .24 & .39 \\
Stress & -.65 & -.45 & .44 & .27 & .48 \\
Money & -.20 & -.34 & .26 & .15 & .19 \\
Growth & -.12 & -.38 & .27 & .03 & .26 \\
Value & -.17 & -.30 & .21 & .11 & .22 \\
Ability & -.13 & -.28 & .17 & .07 & .21 \\
Satisfaction & -.35 & -.33 & .36 & .06 & .35 \\
AC-QoL total & -.52 & -.60 & .51 & .22 & .47 \\
\hline
\end{tabular}

Note. N: number of participants; correlation coefficients greater than $.08, .11$, and .14 are significant at $p$ levels of .05, .01 , and .001 respectively. 
Table 9. Correlations among participants' demographic characteristics and AC-QoL dimensions.

\begin{tabular}{|c|c|c|c|c|c|c|c|}
\hline $\mathrm{N}=591$ & Gender $^{\mathrm{a}}$ & Age & Child age & Education $^{\mathrm{a}}$ & Employment $^{\mathrm{a}}$ & Marital Status $^{a}$ & Child disease severity $^{a}$ \\
\hline Support & -.03 & -.02 & -.12 & -.13 & -.06 & -.03 & -.14 \\
\hline Choice & -.03 & -.08 & -.04 & -.11 & .09 & .10 & -.29 \\
\hline Stress & .05 & -.07 & -.02 & -.08 & .08 & -.15 & -.23 \\
\hline Money & -.06 & .13 & .05 & .20 & .02 & .30 & -.00 \\
\hline Growth & -.12 & -.07 & -.03 & .00 & -.01 & -.14 & -.01 \\
\hline Value & .06 & -.04 & -.11 & -.11 & -.04 & -.14 & .08 \\
\hline Ability & -.18 & -.07 & -.02 & -.14 & -.12 & -.20 & -.03 \\
\hline Satisfaction & -.01 & -.10 & -.08 & -.24 & -.08 & -.19 & -.13 \\
\hline AC-QoL total & -.06 & -.05 & -.07 & -.10 & .00 & -.06 & -.15 \\
\hline
\end{tabular}

Note. N: number of participants; Gender: 0=female, 1=male; Education: 0=below High School, 1=High School or higher; Employment: 0=no,

1=yes; Marital Status: 0=single/divorced/widowed, 1=married/cohabiting; Child disease severity: 0=low-mild, $1=$ high; ${ }^{\text {a }}$ : rank biserial correlation; correlation coefficients greater than $.08, .11$, and .14 are significant at $p$ levels of $.05, .01$, and .001 respectively. 